\title{
ANALISIS KAPASITAS DAN KINERJA LALU LINTAS PADA RUAS JALAN JENDERAL SUDIRMAN JAKARTA
}

\author{
Sarah Haryati ${ }^{1}$ dan Najid ${ }^{2}$ \\ ${ }^{1}$ Program Studi Sarjana Teknik Sipil, Universitas Tarumanagara, Jl. Letjen S. Parman No.1 Jakarta \\ Sarah.325150087@stu.untar.ac.id \\ ${ }^{2}$ Program Studi Sarjana Teknik Sipil, Universitas Tarumanagara, Jl. Letjen S. Parman No.1 Jakarta \\ najid@ft.untar.ac.id
}

Masuk: 10-01-2021, revisi: 10-02-2021, diterima untuk diterbitkan: 11-02-2021

\begin{abstract}
Jakarta as the capital city of Indonesia is the center of economy, culture, and politics. Jenderal Sudirman street always crowded with passing vehicles, traffic snarls up everyday. The causes of these traffic jam is an increase the number of vehicles and cause a change in traffic behavior. Theoretically there is a fudamental relationship between flow, speed, \& density, so the purpose of these research are to analyze and evaluate performance of traffic capacity in various conditions based on Manual Kapasitas Jalan Indonesia 1997 and Greenshields model. Conclusion of the analysis are, after compared with traffic volume, capacity and speed based on MKJI are 3.127,6 pcu/hour and $55,7 \mathrm{~km} / \mathrm{hour}$, but the capacity of the model are selected because it's largest, for sudirman - thamrin it's 8.272,5 pcu/hour, and for thamrin - sudirman it's 8.067,9 pcu/hour, While the calculation of free flow for sudirman - thamrin it's $41.2 \mathrm{~km} / \mathrm{hour}$ the lowest occurs in evening, and for thamrin - sudirman it's 43,9 km/hour the lowest occurs in afternoon. The largest capacity it's used for the next analysis, the next analysis are calculating degree of saturation and level of service, the result shows that the roads are at $C$ and $D$.
\end{abstract}

Keywords: Sudirman; Capacity; Performance; MKJI; Model

\begin{abstract}
ABSTRAK
Jakarta ibu kota negara Indonesia merupakan pusat ekonomi, budaya, dan politik. Sebuah jalan di Jakarta yaitu Jenderal Sudirman selalu dipadati kendaraan. Lalu lintas di Jalan Jenderal Sudirman setiap hari mengalami kemacetan penyebabnya adalah peningkatan jumlah kendaraan di dalam kota dan menyebabkan perubahan perilaku lalu lintas, secara teoritis terdapat hubungan yang mendasar antara arus, kecepatan, dan kepadatan. Tujuan penelitian ini adalah untuk menganalisis, mengevaluasi kinerja dan kapasitas lalu lintas di berbagai macam kondisi, tentu berdasarkan pedoman Manual Kapasitas Jalan Indonesia dan kapasitas model Greenshields. Dari hasil analisis hasil perhitungan kapasitas dan kecepatan arus bebas berdasarkan MKJI sebesar 3.127,6 smp/jam dan 55,7 km/jam setelah dibandingkan dengan volume lalu lintas dipilih kapasitas model yang terbesar yaitu sebesar 8.272,5 smp/jam pada sudirman - thamrin \& 8.067,9 smp/jam pada thamrin - sudirman, dan hasil perhitungan kecepatan arus bebas terendah sebesar 41,2 km/jam di sore hari untuk sudirman - thamrin, sebaliknya thamrin - sudirman terendah sebesar $43,9 \mathrm{~km} / \mathrm{jam}$ di siang hari. Gunakan kapasitas yang terpilih tersebut untuk analisis berikutnya yaitu perhitungan ratio perbandingan arus dan kapasitas (DS) dan tingkat pelayanan yan berada pada tingkat pelayanan huruf $\mathrm{C}$ dan $\mathrm{D}$ di kedua arahnya.
\end{abstract}

Kata Kunci: Sudirman; Kapasitas; Kinerja; MKJI; Model.

\section{PENDAHULUAN}

Indonesia sebagai negara yang sangat luas dengan jumlah populasi penduduk yang padat yaitu sebesar 268.583.016 jiwa (BPS, 2019) membuat negara Indonesia masih memiliki banyak masalah kompleks serta problematika yang belum sepenuhnya teratasi dengan baik, salah satunya ialah masalah kinerja lalu lintas di banyak ruas jalan yang ada di Indonesia terutama di ibu kota negara Indonesia yaitu Jakarta.

Jakarta sebagai Ibu Kota negara Indonesia dengan luas wilayah sebesar 662,33 km² (BPS, 2019) dengan jumlah penduduk sebesar 10.504.100 jiwa (BPS, 2019) adalah kota tempat kedudukan pusat pemerintahan berdiri, dan pusat berbagai macam kegiatan termasuk politik, budaya, dan ekonomi. Hal ini tentu mengakibatkan aktivitas pergerakan penduduk yang tinggi, bukan hanya penduduk asli dari jakarta saja, melainkan dari sekitaran daerah jakarta dan sampai penduduk luar pulau jawa pun juga datang ke Jakarta, mereka menjadikan jakarta sebagai 
magnet perekonomian guna mengumpulkan pundi - pundi uang, mencari peruntungan untuk memenuhi biaya hidup, dan juga harapan untuk mendapatkan kesempatan hidup yang lebih baik. Dengan adanya hal tersebut tentunya permintaan atau keinginan penduduk indonesia khususnya jakarta untuk bergerak serta berpindah tempat dari tempat satu ke tempat lainnya akan menjadi lebih tinggi yang mana akan menciptakaan kebutuhan transportasi yang tinggi juga.

Dengan keaadaan kebutuhan transportasi yang tinggi tersebut, saat ini kita bisa dengan mudah menemukan berbagai macam kendaraan di jalan raya, ada sekitar 20.000.000 (BPS, 2019) kendaraan bermotor yang melintasi jakarta setiap harinya, kendaraan pribadi lah yang paling banyak menghiasi jalan - jalan di ibu kota baik mobil maupun motor, akibat dari kemudahan mendapatkan cicilan biaya kendaraan dan harga kendaraan yang murah, penduduk indonesia bisa dengan mudah membeli dan mendapatkan kendaraan pribadinya sendiri. Oleh karena itu ada banyak sekali dampak yang di timbulkan dan salah satu dampak yang paling terlihat adalah kondisi lalu lintas yang kian padat setiap harinya mengakibatkan kemacetan yang luar biasa di ruas jalan arteri hingga jalan lokal sekalipun (Adiel, 2020).

Kapasitas jalan yang di sediakan pemerintah sudah tidak mampu menampung arus lalu lintas yang terus bertambah padat setiap harinya, faktor lain yang menyebabkan kemacetan lalu lintas adalah penyempitan jalan, kerusakan jalan, faktor dari kendaraan si pengemudi itu sendiri, dan faktor dari lingkungan sekitarnya seperti contohnya hambatan samping, hambatan karena kendaraan yang tak bermotor, dan hambatan yang dihasilkan oleh pejalan kaki. Permasalahan lalu lintas jalan raya merupakan suatu permasalahan yang kompleks dalam dunia transportasi perkotaan (Eko, 2010), untuk menyelesaikan permasalahan lalu lintas yang di timbulkan dari banyak faktor diatas memang tidak mudah tetapi dengan adanya upaya rekayasa lalu lintas dan manajemen lalu lintas yang terkoordinasi dengan baik, cepat serta tepat dari pemerintah, masalah lalu lintas yang kita hadapi saat ini baik di jakarta maupun seluruh indonesia tentunya bisa membantu mengurangi masalah lalu lintas yang ada.

Tujuan dari penulisan laporan mengenai analisis kapasitas dan kinerja lalu lintas di Jalan Jenderal Sudirman, yang mana jalan ini terletak di pusat kota Jakarta dan merupakan lokasi pusat bisnis (financial district) adalah untuk mendapatkan dan mengevaluasi hasil kapasitas dan kecepatan arus bebas berdasarkan MKJI, menganalisis kinerja lalu lintas dengan berbagai macam kondisi, dan membuat model aliran lalu lintas serta hubungan kecepatan, kepadatan, dan arus lalu lintasnya. Keadaan saat ini dengan keadaan di tahun berdasarkan MKJI yaitu 1997 tentu nya telah jauh berbeda, maka dari itu diperlukan revisi MKJI di keadaan dan waktu yang berbeda.

Dengan melakukan analisis yang berpacu kepada MKJI (Manual Kapasitas Jalan Indonesia) dan Model pendekatan lalu lintas melalui model Linier Greenshields, memberikan pedoman untuk mendapatkan kapasitas dari suatu ruas jalan (Dikdik, 2013) dan dapat terlihat kebutuhan dan pemenuhan pelayanan jaringan jalan yang digunakan untuk mengatasi masalah terutama kemacetan di kota jakarta. Dari latar belakang di atas masalah yang dapat kita identifikasikan ialah mengenai kapasitas jalan, kondisi, dan komposisi lalu lintas jalan yang saat ini telah berbeda dengan kondisi tahun 1997, analisis volume lalu lintas dari hasil survei sering kali berbeda dan hasilnya lebih besar dari kapasitas jalan berdasarkan MKJI 1997, sehingga di perlukan penelitian serta perhitungan kapasitas dan kinerja lalu lintas di kondisi saat ini dan kondisi di saat - saat tertentu (Najid, 2019) dan rumusan masalah yang telah di tetapkan ialah di lakukan analisis dan pengumpulan data arus lalu lintas pada ruas jalan Jenderal Sudirman yaitu di kedua arah, masing - masing arah yaitu pertama pada ruas jalan Sudirman arah Thamrin berada tepat di bawah JPO (Jembatan Penyebrangan Orang) sudirman dan ruas jalan sebaliknya Thamrin arah Sudirman berada pada titik pos pollisi yang ada di depan stasiun kereta sudirman. Analisis di lakukan pada waktu yang berbeda yaitu pagi, siang, dan sore.

\section{Kapasitas jalan}

Kapasitas menurut MKJI di definisikan sebagai arus maksimum melalui satu titik di jalan yang dapat dipertahankan per satuan jam pada kondisi tertentu. Untuk jalan dua lajur dua arah, kapasitas ditentukan untuk arus dua arah, tetapi untuk jalan dengan banyak lajur, arus dipisah per arah dan kapasitas ditentukan per lajur. Persamaan dasar untuk menentukan kapasitas adalah sebagai berikut :

$$
\mathrm{C}=\mathrm{C}_{\mathrm{o}} \times \mathrm{FC}_{\mathrm{w}} \times \mathrm{FC}_{\mathrm{sp}} \times \mathrm{FC}_{\mathrm{sf}} \times \mathrm{FC}_{\mathrm{cs}}
$$

Keterangan:

C : Kapasitas (smp/jam).

$\mathrm{C}_{\mathrm{O}}$ : Kapasitas dasar (smp/jam).

$\mathrm{FC}_{\mathrm{w}}$ : Faktor penyesuaian lebar jalan.

$\mathrm{FC}_{\mathrm{sp}}$ : Faktor penyesuaian pemisah arah (hanya untuk jalan tak terbagi). 
$\mathrm{FC}_{\text {sf }}$ : Faktor penyesuaian hambatan samping dan bahu jalan/kereb.

$\mathrm{FC}_{\mathrm{cs}}$ : Faktor penyesuaiam ukuran kota.

\section{Kecepatan arus bebas}

Menurut MKJI 1997 kecepatan arus bebas adalah kecepatan rata - rata teoritis $(\mathrm{km} / \mathrm{jam})$ lalu lintas pada kerapatan sama dengan nol, yaitu tidak ada kendaraan yang lewat. Penentuan kecepatan arus bebas pada kondisi sesungguhnya dapat dihitung dengan menggunakan rumus sebagai berikut :

Keterangan:

$$
\mathrm{FV}=\left(\mathrm{FV}_{\mathrm{o}}+\mathrm{FV}_{\mathrm{w}}\right) \times \mathrm{FFV}_{\mathrm{sp}} \mathrm{xFV_{ \textrm {es } }}
$$

FV : Kecepatan arus bebas kendaraan $(\mathrm{km} / \mathrm{jam})$.

$\mathrm{FV}_{\mathrm{o}}$ : Kecepatan arus bebas dasar kendaraan ( $\left.\mathrm{km} / \mathrm{jam}\right)$.

$\mathrm{FV}_{\mathrm{w}}$ : Penyesuaian lebar jalur lalu lintas efektif (km/jam) penjumlahan.

$\mathrm{FFV}_{\mathrm{sf}}$ : Faktor penyesuaian kondisi hambatan samping.

$\mathrm{FFV}_{\mathrm{cs}}$ : Faktor penyesuaian ukuran kota.

\section{Derajat kejenuhan}

Menurut MKJI (1997), derajat kejenuhan adalah perbandingan rasio arus (smp/jam) terhadap kapasitas (smp/jam) dan digunakan sebagai faktor kunci dalam menilai dan menentukan tingkat kineja suatu segmen jalan. Nilai derajat kejenuhan menunjukan apakah segmen jalan akan mempunyai masalah kapasitas atau tidak. Berikut ini adalah rumus dari derajat kejenuhan :

$$
D S=\mathrm{V} / \mathrm{C}
$$

Keterangan:

DS : Derajat kejenuhan.

$\mathrm{V}$ : Arus lalu lintas.

C : Kapasitas.

\section{Tingkat pelayanan jalan}

Tingkat pelayanan jalan (Level Of Service/LOS) terdapat dua definisi yaitu tingkat pada suatu ruas jalan yaitu tingkat pelayanan tergantung arus dan tingkat pelayanan tergantung fasilitas (Ofyar Z Tamin, 2008). Tingkat pelayanan ruas jalan yang tergantung pada arus lalu lintas berkaitan dengan kecepatan operasi yang tergantung pada perbandingan antara arus dan kapasitas jalan. MKJI membagi tingkat pelayanan jalan menjadi 6 keadaan (A, $\mathrm{B}, \mathrm{C}, \mathrm{D}, \mathrm{E}, \mathrm{F})$ dengan memplot titik data kecepatan dan volume (V/C) kita dapat menentukan tingkat pelayanan yang ada di ruas jalan yang sedang di tinjau, selain dengan memplot hasil hubungan kecepatan dan volume, kita juga bisa langsung menggunkan ratio nilai V/C berdasarkan nilai V/C (derajat kejenuhan) dengan menggunakan gambar 1 grafik di bawah ini yaitu sajian gambaran grafik dan tabel tingkat pelayanan level of service.

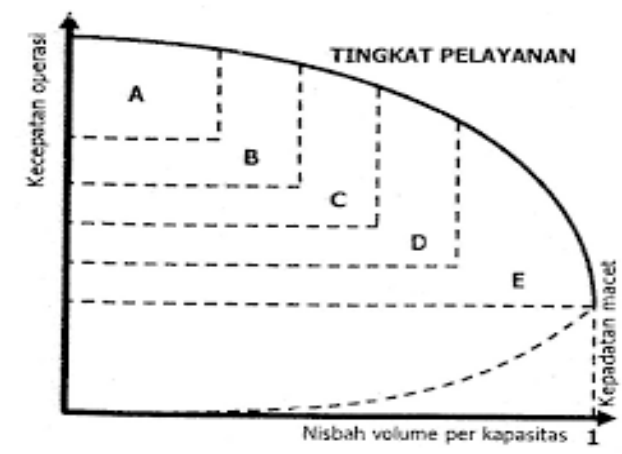

Gambar 1. Grafik tingkat pelayanan

Sumber : Buku perencanaan, pemodelan dan rekayasa transportasi (Ofyar Z Tamin, 2008) 


\section{Model greenshields}

Model greenshields adalah model / cara yang paling pertama digunakan dalam upaya mengamati perilaku lalu lintas. Model umum ini bekerja dengan menghubungkan kecepatan, arus, dan kepadatan dan hasilnya ialah hubungan ketiganya bersifat linier.

\section{Persamaan hubungan antara kecepatan - kepadatan}

Model Greenshields menggambarkan persamaan hubungan kecepatan dengan kepadatan menggunakan rumus :

$$
\mathrm{S}=\mathrm{Sff}-\left(\frac{S f f}{D j}\right) \times \mathrm{D}
$$

Keterangan:

$\mathrm{S} \quad: \operatorname{Kecepatan}(\mathrm{km} / \mathrm{jam}), \frac{V}{D}$.

Sff : Kecepatan pada saat kondisi arus lalu lintas sangat rendah, kondisi kecepatan mendekati nol, kecepatan arus bebas $(\mathrm{km} / \mathrm{jam})$.

Dj : Kepadatan pada saat kondisi arus lalu lintas macet total (kend/jam).

\section{METODE PENELITIAN}

Pada bab ini akan dibahas tahap dalam penelitian yaitu tahapan jalannya penelitian yang nanti akan menjadi panduan dalam pelaksanaan penelitian sebenarnya sehingga diharapkan penelitian yang akan kita lalui, berjalan dengan baik dan sistematis. Pada awal penelitian setelah menetapkan tujuan, masalah, dan metode pengumpulan, akan dilakukan serangkaian pengamatan secara langsung melakukan pembahasan masalah yang ada di titik lokasi pengamatan yang telah di tentukan yaitu di Jalan Jenderal Sudirman, Jakarta. Pengumpulan data terdiri dari 2 jenis data yaitu, Data Sekunder dan Data Primer.

Data sekunder adalah data yag didapat / berasal dari data literatur (data yang bersumber dari acuan berbagai macam aktivitas di dunia pendidikan contohnya seperti buku - buku pedoman, jurnal - jurnal ilmiah, kamus, berbagai macam artikel di internet yang isi nya berhubungan dengan dengan hal yang akan dibahas) dan data instansional (pengumpulan data yang dilakukan melalui survei pada instansi - instansi terkait, dengan tujuan mendapatkan data - data peraturan, pedoman pelaksanaan dan standart aturan yang telah di keluarkan dan berlaku). Sedangkan data primer adalah data yang di didapat / berasal dari data observasi dan penelitian sebelumnya " Pengaruh electronic road pricing terhadap perbaikkan pelayanan waktu tunggu dan waktu tempuh transjakarta pada ruas jalan Jenderal Sudirman " (Adiel, 2020), setelah seluruh data di kumpulkan dan didapatkan lalu akan dibuatkan perhitungan sesuai dengan pedoman MKJI 1997 dan model, lalu dituangkan hasilnya berupa grafik hubungan antara volume, kecepatan, dan kepadatan kemudian akan dilakukan indentifikasi masalah yang ada dan yang terjadi saat itu.

Dari data hasil pengamatan yang kemudian akan di modifikasi, pengambilan data hasil pengamatan akan didapatkan data kecepatan, kepadatan, dan volume kendaraan, pengambilan data secara langsung tentunya akan didapatkan hasil berupa informasi mengenai tingkat pelayanan pada ruas jalan tersebut dan bagaimana kinerja lalu lintasnya.

\section{Metode pengumpulan data}

Survei yang dilakukan oleh pengamat sebelumnya dilakukan dengan cara pengamatan langsung di tempat dan merupakan salah satu metode primer, dalam pengerjaan laporan ini diperlukan banyak hal berupa data - data yang valid dengan tujuan agar kita dapat menganalisa dan menarik kesimpulan mengenai kinerja ruas jalan tersebut contohnya adalah data jumlah kendaraan yang lewat, waktu yang di tempuh kendaraan tersebut, hambatan samping, kecepatan rata - rata, dan lainya sehingga kita dapat menghitung dan mendapatkan hasil kapasitas jalan raya, kecepatan arus bebas kendaraan, kecepatan tempuh, derajat kejenuhan dan tingkat pelayanan pada ruas Jalan Jenderal Sudirman terhadap kinerja lalu lintas di jalan tersebut.

\section{Metode pengamatan langsung}

Metode pengamatan secara langsung merupakan pengumpulan data secara langsung dilapangan dengan panca indera kita langsung, tentang bagaimana kejadian secara teknis yang terjadi tentang bagaimana kejadian secara teknis yang terjadi. Dalam tugas akhir ini yang akan diamati di ruas Jalan Jenderal Sudirman yang terdiri dari beberapa hal yaitu karakteristik jalan, jalur, sarana dan prasarana, hambatan samping, jenis jalan dan sebagainya. 


\section{Metode analisis dan regresi linear}

Regresi linear adalah alat statistik yang dipergunakan untuk mengetahui pengaruh antara satu atau beberapa variabel (variabel bebas) terhadap satu buah variabel (variabel terikat), metode yang digunakan dalam perhitungan laporan ini adalah metode analisis regresi linear sederhana yaitu dengan masing - masing satu buah variabel bebas dan terikat, persamaan umumnya adalah dengan $(\mathrm{Y})$ adalah variabel terikat, $(\mathrm{X})$ adalah variabel bebas, koefisien a adalah konstanta. Metode ini akan di gunakan untuk membuat persamaan hubungan Kecepatan, Kepadana, dan Volume lalu lintas dengan Model.

$$
Y=a+b X
$$

\section{HASIL DAN PEMBAHASAN}

Lokasi yang di gunakan untuk survei pengumpulan data yaitu berada di Jalan Jenderal Sudirman, tepatnya pada titik pertama adalah kantor pos polisi stasiun kereta sudirman dan titik kedua adalah JPO (Jembatan Penyeberangan Orang) sudirman, lokasi ini merupakan lokasi yang banyak dilalui kendaraan dan pengguna jalan. Data - data transportasi yang telah disurvei dan didapatkan dari data penelitian sebelumnya di lapangan adalah data mengenai kondisi lalu lintas, volume, kecepatan rata - rata, jalur, lajur, lebar jalan, lebar trotoar dan hambatan samping, data didapat dari hasil penelitian terdahulu dengan observasi pengamatan secara langsung menggunakan Manual Hand Tally dan stop watch dengan menghitung arus lalu lintas, kecepatan kendaraan yang melewati titik jalan tersebut.

Kendaraan yang diamati ialah kendaraan ringan (Light Vehicle), kendaraan rerat (Heavy Vehicle), sepeda motor (Motor Cycle). Pengumpulan data volume kendaraan atau banyaknya kendaraan yang lewat pada garis pengamatan dilakukan dengan cara mencatat semua kendaraan yang melewati titik pengamatan tersebut. Selama waktu pengamatan dibantu dengan pemakaian alat hitung manual, pencatatan dilakukan untuk setiap interval waktu 15 menit selama 2 jam pengamatan dan dilakukan selama 3 waktu yaitu pagi pukul $06.00-08.00$, siang pukul 12.00 - 14.00, dan sore menjelang malam hari pukul $17.00-19.00$ sehingga akan didapatkan 8 pasangan data untuk setiap jenis kendaraannya, pengamatan dilakuan pada hari - hari kerja saat ruas jalan banyak di lewati / padat dengan pengguna yaitu seperti hari senin, selasa, rabu, dan kamis dengan $200 \mathrm{~m}$ jarak yang di tempuh kendaraan. Pengamat tidak hanya mengamati ketiga jenis kendaraan diatas saja, melainkan juga mengamati keadaan di sekitar daearah ruas jalan tersebut seperti hambatan samping, jenis hambatan samping yang diamati ialah seperti kendaraan tidak bermotor, kendaraan yang berhenti, kendaraan yang melawan arah, pejalan kaki yang menyebrang, dan kendaraan yang keluar masuk. Hambatan samping juga akan digunakan untuk mencari kapasitas lalu lintas, tentunya survei ini tidak dilakukan sendiri tetapi dilakukan oleh 2 orang.

\section{Karakteristik jalan}

Jalan Jenderal Sudirman merupakan tipe jalan yang memiliki 6 lajur 2 arah terbagi atau 6/2 D, dengan lebar jalan 18,5 m, masing - masing jalur cepat memiliki lebar kurang lebih 3 m, jalur busway di sisi kiri, jalur lambat di sisi kanan dan jalur pedestrian yang cukup luas lengkap dengan tanamannya, jalan menggunakan median sehingga kondisi badan jalan terbagi, jarak antara kereb dengan trotoar adalah kurang lebih $2 \mathrm{~m}$, jumlah penduduk di kota jakarta tempat dimana jalan jenderal sudirman berada yaitu lebih dari sekitar 10 juta jiwa, letak jalan jenderal sudirman ialah berada di tengah pusat kota merupakan kawasan perkantoran dan komersil tentunya sangat berpengaruh juga terhadap aktifitas hambatan samping pada jalan tersebut, dari hasil analisis kelas hambatan ke dua arah Jalan Jenderal Sudirman pada waktu pagi, siang dan sore adalah sangat rendah / Very Low.

Pada tabel 1 dibawah ini adalah sajian data volume, kecepatan, dan kepadatan dari hasil survei yang melewati ruas Jalan Jenderal Sudirman (Sudirman arah Thamrin) sejauh $200 \mathrm{~m}$ pada waktu pagi, siang, dan sore. 
Tabel 1. Hasil survei \& analisis ruas Jalan Jenderal Sudirman, Sudirman arah Thamrin (pagi, siang, \& sore)

\begin{tabular}{|c|c|c|c|c|c|c|c|c|c|c|c|}
\hline \multirow{2}{*}{ Waktu } & \multicolumn{3}{|c|}{ Pagi } & \multicolumn{4}{|c|}{ Siang } & \multicolumn{4}{|c|}{ Sore } \\
\hline & $\begin{array}{l}\text { Vol } \\
\text { (V) }\end{array}$ & $\begin{array}{c}\mathrm{Kec} \\
(\mathrm{S})\end{array}$ & $\operatorname{Kep}(\mathrm{D})$ & Waktu & $\begin{array}{l}\text { Vol } \\
\text { (V) }\end{array}$ & $\begin{array}{c}\mathrm{Kec} \\
(\mathrm{S})\end{array}$ & $\begin{array}{r}\text { Kep } \\
\text { (D) }\end{array}$ & Waktu & $\begin{array}{l}\text { Vol } \\
\text { (V) }\end{array}$ & $\begin{array}{c}\mathrm{Kec} \\
(\mathrm{S})\end{array}$ & Kep (D) \\
\hline $06.00-07.00$ & 4.557 & 38,47 & 118,4 & $12.00-13.00$ & 4.898 & 37,54 & 130,49 & $17.00-18.00$ & 5.005 & 31,99 & 156,42 \\
\hline $06.15-07.15$ & 4.474 & 37,96 & 117,85 & $12.15-13.15$ & 4.896 & 37,54 & 130,44 & $17.15-17.15$ & 5.135 & 31,37 & 163,65 \\
\hline $06.30-07.30$ & 4.469 & 37,45 & 119,31 & $12.30-13.30$ & 4.986 & 37,24 & 133,88 & $17.30-17.30$ & 5.279 & 31,64 & 166,84 \\
\hline $06.45-07.45$ & 4.507 & 37,05 & 121,65 & $12.45-13.45$ & 5.010 & 37,39 & 133,99 & 17.45 - 17.45 & 5.425 & 31,37 & 172,89 \\
\hline $07.00-08.00$ & 4.481 & 36,78 & 121,82 & $13.00-14.00$ & 4.983 & 37,34 & 133,45 & $18.00-19.00$ & 5.449 & 30,38 & 179,34 \\
\hline
\end{tabular}

Dari tabel 1 hasil survei ruas sudiman arah thamrin di atas volume terbesar pada pagi hari terjadi pada pukul 06.45 - 07.45 yaitu sebesar 4.507, siang hari pada pukul 12.45 -13.45 sebesar 5.010, pada sore hari pukul 18.00 -19.00 sebesar 5.449 .

Pada tabel 2 dibawah ini adalah sajian data volume, kecepatan, dan kepadatan dari hasil survei yang melewati ruas jalan jenderal sudirman (thamrin arah sudirman) sejauh $200 \mathrm{~m}$ pada waktu pagi, siang, dan sore.

Tabel 2. Hasil survei \& analisis ruas Jalan Jenderal Sudirman, Thamrin arah Sudirman (pagi, siang, \& sore)

\begin{tabular}{|c|c|c|c|c|c|c|c|c|c|c|c|}
\hline \multirow{2}{*}{ Waktu } & \multicolumn{3}{|c|}{ Pagi } & \multicolumn{4}{|c|}{ Siang } & \multicolumn{4}{|c|}{ Sore } \\
\hline & $\begin{array}{l}\text { Vol } \\
\text { (V) }\end{array}$ & $\begin{array}{l}\mathrm{Kec} \\
(\mathrm{S})\end{array}$ & $\begin{array}{l}\text { Kep } \\
\text { (D) }\end{array}$ & Waktu & $\begin{array}{l}\text { Vol } \\
\text { (V) }\end{array}$ & $\begin{array}{c}\mathrm{Kec} \\
(\mathrm{S})\end{array}$ & $\begin{array}{l}\text { Kep } \\
\text { (D) }\end{array}$ & Waktu & $\begin{array}{l}\text { Vol } \\
\text { (V) }\end{array}$ & $\operatorname{Kec}(\mathrm{S})$ & Kep (D) \\
\hline $06.00-07.00$ & 6.065 & 36,89 & 164,36 & $12.00-13.00$ & 6.153 & 35,08 & 175,39 & $17.00-18.00$ & 5.818 & 33,85 & 171,86 \\
\hline $06.15-07.15$ & 6.067 & 36,42 & 166,57 & $12.15-13.15$ & 6.321 & 34,64 & 182,47 & $17.15-17.15$ & 5.850 & 32,96 & 177,45 \\
\hline $06.30-07.30$ & 6.142 & 36,42 & 168,63 & $12.30-13.30$ & 6.444 & 33,96 & 189,73 & $17.30-17.30$ & 5.943 & 32,28 & 184,06 \\
\hline $06.45-07.45$ & 6.106 & 36,37 & 167,87 & $12.45-13.45$ & 6.559 & 33,79 & 194,05 & $17.45-17.45$ & 6.034 & 32,49 & 187,79 \\
\hline $07.00-08.00$ & 6.024 & 37,05 & 162,61 & $13.00-14.00$ & 6.700 & 34,64 & 193,41 & $18.00-19.00$ & 6.110 & 32,49 & 188,06 \\
\hline
\end{tabular}

Dari tabel 2 hasil survei ruas thamrin arah sudirman di atas volume terbesar pada pagi hari terjadi pada pukul 06.30 - 07.30 yaitu sebesar 6.142, siang hari pada pukul 13.00 - 14.00 sebesar 6.700, pada sore hari pukul 18.00 19.00 sebesar 6.110 .

\section{Analisis perhitungan kecepatan arus bebas}

Menurut MKJI 1997 kecepatan arus bebas didefinisikan sebagai kecepatan pada saat tingkat arus nol, hasil perhitungan kecepatan arus bebas pada ruas jalan jenderal sudirman adalah:

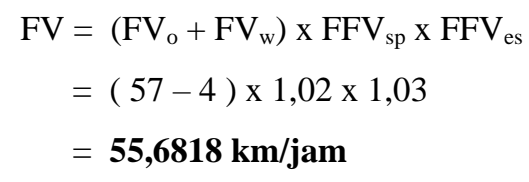

\section{Analisis perhitungan kapasitas}

Perhitungan kapasitas ruas jalan di lakukan dengan berpedoman kepada proses perhitungan yang ada pada Manual Kapasitas Jalan Indonesia beserta tabel - tabel yang ada pada MKJI 1997 untuk jalan di perkotaan dan hasil kapasitas untuk ruas jalan jenderal sudirman adalah: 


$$
\begin{aligned}
& \mathrm{C}=\mathrm{C}_{0} \times \mathrm{FC}_{\mathrm{W}} \times \mathrm{FC}_{\mathrm{sp}} \times \mathrm{FC}_{\mathrm{sf}} \times \mathrm{FC}_{\mathrm{CS}} \\
& =(1.650 \times 3) \times 0,92 \times 1,00 \times 1,01 \times 1,02 \\
& =4.691,53 \mathrm{smp} / \mathrm{jam}
\end{aligned}
$$

\section{Model greenshields}

Dari hasil data survei di perhitungkan juga kinerja lalu lintas berdasarkan model greenshields sehingga bisa mendapatkan nilai kapasitas berdasarkan model dan persamaan hubungan ke 3 parameter hubungan matematis antara volume, kecepatan, dan kepadatan lalu lintas di ruas jalan jenderal sudirman model greenshields, dari data kecepatan dan kepadatan di dapatkan nilai Sff (kecepatan saat kondisi arus lalu lintas sangat rendah pada kondisi kepadatan mendakati nol, kecepatan mendekati nol), dan Dj (kepadatan pada kondisi arus lalu lintas macet total), masukkan nilai Sff dan Dj ke dalam rumus model greenshields untuk medapatkan persamaan hubungan kecepatan, kepadatan, dan volume. Setelah itu kita juga bisa mencari nilai kapasitas berdasarkan model, lakukan untuk kedua arah.

Berikut dibawah ini adalah tabel 3 hasil rekapitulasi perhitungan Sff, Dj, dan B pada ruas jalan jenderal sudirman di kedua arah pada waktu pagi, siang, sore, dan gabungan.

Tabel 3. Nilai Sff, B dan Dj kedua arah ruas Jalan Jenderal Sudirman (pagi, siang, sore, dan gabungan)

\begin{tabular}{ccccccc}
\hline \multirow{2}{*}{ Waktu } & \multicolumn{3}{c}{ Sudirman - Thamrin } & \multicolumn{3}{c}{ Thamrin - Sudirman } \\
\cline { 2 - 7 } & Sff & $\mathrm{B}$ & $\mathrm{Dj}$ & $\mathrm{Sff}$ & $\mathrm{B}$ & $\mathrm{Dj}$ \\
\hline Pagi & 77,704 & $-0,335$ & 231,952 & 56,589 & $-0,120$ & 470,790 \\
\hline Siang & 45,803 & $-0,063$ & 722,445 & 43,930 & $-0,060$ & 734,615 \\
\hline Sore & 41,624 & $-0,061$ & 680,131 & 49,590 & $-0,092$ & 536,688 \\
\hline Gabungan & 49,186 & $-0,094$ & 524,222 & 55,850 & $-0,119$ & 468,615 \\
\hline
\end{tabular}

Dari tabel 3 diatas untuk mendapatkan nilai Sff, Dj dan B dilakukan perhitungan dengan excel yaitu dengan memasukkan data hasil survei kepadatan (X) dan kecepatan (Y) dan dihitung dengan menggunakan rumus di bawah ini:
1. Sff $=\frac{\sum X^{2} \cdot \sum Y-\sum X \cdot \sum X Y}{n \cdot \sum X^{2} \cdot\left(\sum X\right)^{\wedge} 2}$
2. $\mathrm{B}=\frac{n \cdot \sum X Y-\sum X \cdot \sum Y}{n \cdot \sum x^{2} \cdot\left(\sum x\right)^{\wedge} 2}$
3. $\mathrm{Dj}=\frac{-S f f}{B}$

Dibawah ini adalah tabel 4 hasil rekapitulasi perhitungan persamaan hubungan antara kecepatan dan kepadatan midel greenshields pada ruas jalan jenderal sudirman di kedua arah pada waktu pagi, siang, sore, dan gabungan.

Tabel 4. Persamaan hubungan karakteristik antara kecepatan - kepadatan (S - D) lalu lintas untuk model greenshields di Jalan Jenderal Sudirman di kedua arah

\begin{tabular}{ccc}
\hline \multirow{2}{*}{ Waktu } & Sudirman - Thamrin & Thamrin - Sudirman \\
\cline { 2 - 3 } & kecepatan - kepadatan & kecepatan - kepadatan \\
\hline Pagi & $\mathrm{S}=(77,704-0,335 \mathrm{D})$ & $\mathrm{S}=(56,589-0,120 \mathrm{D})$ \\
\hline Siang & $\mathrm{S}=(45,803-0,063 \mathrm{D})$ & $\mathrm{S}=(43,930-0,060 \mathrm{D})$ \\
\hline Sore & $\mathrm{S}=(41,624-0,061 \mathrm{D})$ & $\mathrm{S}=(49,590-0,092 \mathrm{D})$ \\
\hline Gabungan & $\mathrm{S}=(49,186-0,094 \mathrm{D})$ & $\mathrm{S}=(55,850-0,119 \mathrm{D})$ \\
\hline
\end{tabular}

Untuk mendapatkan hasil tabel 4 diatas setelah menghitung hasil Sff, Dj, dan B, nilai - nilai tersebut dapat di masukkan ke dalam persamaan hubungan ke 3 parameter volume, kecepatan, dan kepadatan, untuk membuat grafik hubungan kecepatan dengan kepadatan masukkan niali Sff, Dj dan B ke dalam rumus sebagai berikut:

1. $\mathrm{S}=\mathrm{Sff}-\left(\frac{S f f}{D j}\right) \times \mathrm{D}$ 
Tabel 5 dan Tabel 6 dibawah ini adalah ringkasan hasil rekapitulasi perhitungan kapasitas berdasarkan MKJI dan Model greenshields pada ruas jalan jenderal sudirman di kedua arah pada waktu pagi, siang, sore, dan gabungan yang di.

Tabel 5. Rekapitulasi perhitungan kapasitas model greenshields dan kapasitas berdasarkan MKJI pada ruas Jalan Jenderal Sudirman, Sudirman - Thamrin

\begin{tabular}{|c|c|c|c|c|c|}
\hline Waktu & $\mathbf{R}^{2}$ & $\begin{array}{c}\text { Volume } \\
\text { (smp/jam) }\end{array}$ & $\langle/\rangle$ & $\begin{array}{c}\text { Kapasitas } \\
\text { Model } \\
\text { (smp/jam) }\end{array}$ & $\begin{array}{c}\text { Kapasitas } \\
\text { MKJI } \\
\text { (smp/jam) }\end{array}$ \\
\hline Pagi & 0,804 & 4.507 & $<$ & $4.507,904$ & $4.691,53$ \\
\hline Siang & 0,819 & 5.010 & $<$ & $8.272,535$ & $4.691,53$ \\
\hline Sore & 0,798 & 5.449 & $<$ & $7.077,44$ & $4.691,53$ \\
\hline Gabungan & 0,851 & 5.449 & $<$ & $6.446,124$ & $4.691,53$ \\
\hline
\end{tabular}

Tabel 6. Rekapitulasi perhitungan kapasitas model greenshields dan kapasitas berdasarkan MKJI pada ruas Jalan Jenderal Sudirman, Thamrin - Sudirman

\begin{tabular}{|c|c|c|c|c|c|}
\hline Waktu & $\mathbf{R}^{2}$ & $\begin{array}{c}\text { Volume } \\
\text { (smp/jam) }\end{array}$ & $\langle/\rangle$ & $\begin{array}{c}\text { Kapasitas } \\
\text { Model } \\
\text { (smp/jam) }\end{array}$ & $\begin{array}{c}\text { Kapasitas } \\
\text { MKJI } \\
\text { (smp/jam) }\end{array}$ \\
\hline Pagi & 0,906 & 6.142 & $<$ & $6.660,389$ & $4.691,53$ \\
\hline Siang & 0,581 & 6.700 & $<$ & $8.067,913$ & $4.691,53$ \\
\hline Sore & 0,877 & 6.110 & $<$ & $6.653,593$ & $4.691,53$ \\
\hline Gabungan & 0,574 & 6.700 & $<$ & $6.543,018$ & $4.691,53$ \\
\hline
\end{tabular}

Dari tabel 5 dan tabel 6 di atas adalah apabila volume lalu lintas lebih kecil dari kapasitas model greenshields maka yang di gunakan adalah kapasitas dari model greenshields, kapasitas MKJI tidak lagi digunakan untuk perhitungan selanjutnya. Dari hasil rekapitulasi perhitungan kapasitas model greenshields di pilih yang paling besar ialah kapasitas dari model yaitu untuk ruas jalan sudirman - thamrin kapasitas pada siang hari sebesar 8.272,535 smp/jam dan untuk ruas jalan thamrin - sudirman pada siang hari 8.067,913 smp/jam. Volume di ambil dari data hasil survey kedua arah di pilih volume yang terbesar, untuk mendapatkan nilai $\mathrm{R}^{2}$ dan kapasitas model rumus yang digunakan adalah sebagai berikut:

1. $\mathrm{R}^{2}$

$$
=\left(\frac{n \cdot \sum X \cdot Y-\sum X \cdot \sum Y}{\sqrt{\left[\left(n \cdot \sum X^{2}-\left(\sum X\right)^{2}\right) \cdot\left(n \cdot \sum Y^{2}-\left(\sum Y\right)^{\wedge} 2\right)\right.}}\right)^{\wedge} 2
$$

2. Kapasitas $=\frac{D j \times s f f}{4}$

Berikut ini gambar 2 adalah gambaran grafik hasil hubungan kecepatan dengan kepadatan model greenshields pagi (biru), siang (merah), dan sore (hijau) pada jalan jenderal sudirman, sudirman arah thamrin.

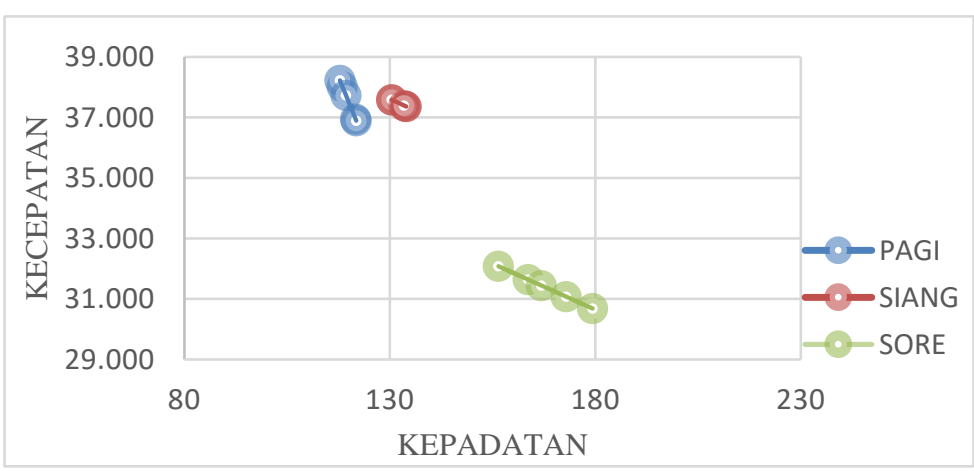

Gambar 2. Grafik hubungan kecepatan - kepadatan model greenshields pada ruas jalan Jenderal Sudirman, Sudirman arah Thamrin (pagi, siang, dan sore) 
Pada gambar 2 grafik hubungan kecepatan - kepadatan model greenshields, sudirman arah thamrin (pagi, siang dan sore) diatas hasilnya adalah kecepatan tertinggi terjadi pada waktu pagi hari dibandingkan dengan siang, kecepatan pada pagi hari lebih tinggi, dan kecepatan terendah dengan kepadatan tinggi terjadi pada sore hari.

Berikut ini gambar 3 adalah gambaran grafik hasil hubungan kecepatan dengan kepadatan model greenshields gabungan (biru) pada jalan jenderal sudirman, sudirman arah thamrin.

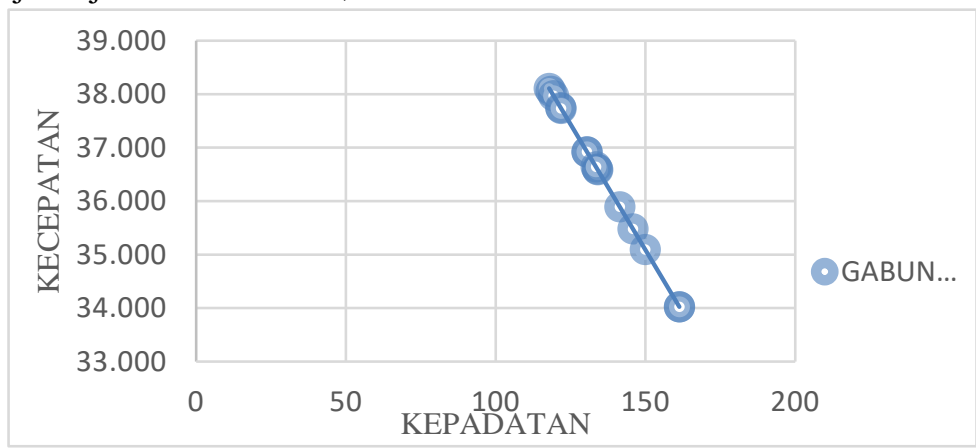

Gambar 3. Grafik hubungan kecepatan - kepadatan model greenshields pada ruas Jalan Jenderal Sudirman, Sudirman arah Thamrin (gabungan)

Pada gambar 3 grafik hubungan kecepatan - kepadatan model greenshields, sudirman arah thamrin (gabungan) diatas hasilnya adalah kecepatan tinggi berada pada kepadatan yang lebih rendah, sebaliknya kecepatan rendah berada pada kepadatan yang tinggi.

Berikut ini gambar 4 adalah gambaran grafik hasil hubungan kecepatan dengan kepadatan model greenshields pagi (biru), siang (merah), dan sore (hijau) pada arah sebaliknya ruas jalan jenderal sudirman, thamrin arah sudirman.

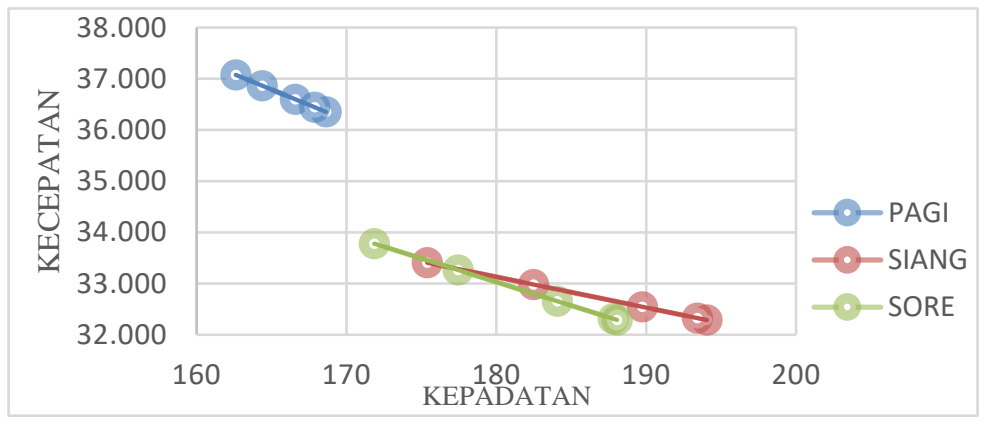

Gambar 4. Grafik hubungan kecepatan - kepadatan model greenshields pada ruas Jalan Jenderal Sudirman, Thamrin arah Sudirman (pagi, siang, dan sore)

Pada gambar 4 grafik hubungan kecepatan - kepadatan model greenshields, thamrin arah sudirman (pagi, siang dan sore) diatas hasilnya adalah kecepatan tertinggi terjadi pada waktu pagi hari, siang dan sore hari berada pada kecepatan yang rendah dengan kepadatan yang tinggi dan yang terendahnya adalah terjadi pada sore hari.

Berikut ini gambar 5 adalah gambaran grafik hasil hubungan kecepatan dengan kepadatan model greenshields gabungan (biru) pada jalan jenderal sudirman, thamrin arah sudirman.

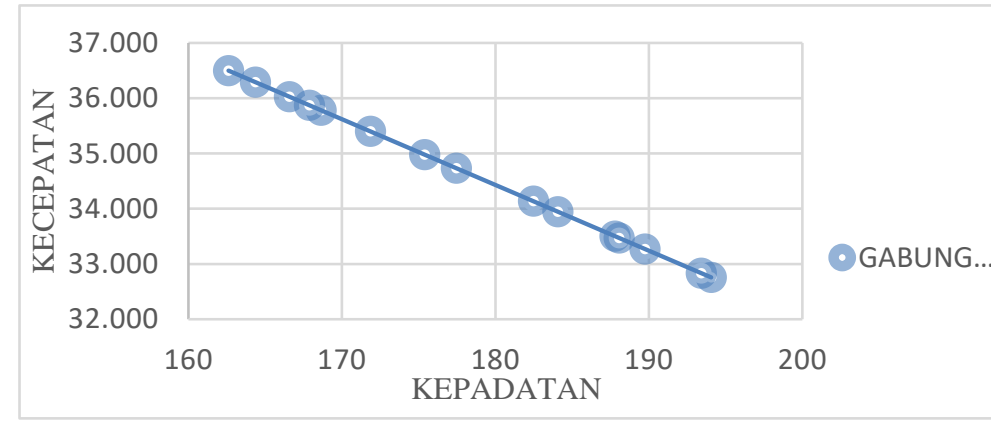

Gambar 5. Grafik hubungan kecepatan - kepadatan model greenshields pada ruas Jalan Jenderal Sudirman, Thamrin arah Sudirman (gabungan) 
Pada gambar 5 grafik hubungan kecepatan - kepadatan model greenshields, thamrin arah sudirman (gabungan) diatas hasilnya adalah kecepatan tinggi berada pada kepadatan yang lebih rendah, sebaliknya kecepatan rendah berada pada kepadatan yang tinggi.

\section{Derajat kejenuhan}

Menurut MKJI (1997), derajat kejenuhan adalah perbandingan rasio arus (smp/jam) terhadap kapasitas (smp/jam) dan digunakan sebagai faktor kunci dalam menilai dan menentukan tingkat kinerja suatu segmen jalan. Nilai derajat kejenuhan menunjukan apakah segmen jalan akan mempunyai masalah kapasitas atau tidak. Berikut ini adalah hasil derajat kejenuhan untuk volume terbesar di pagi, siang, sore, dan gabungan.

Tabel 7 dibawah ini adalah hasil perhitungan derajat kejenuhan berdasarkan MKJI pada ruas jalan jenderal sudirman di kedua arah pada waktu pagi, siang, sore, dan gabungan yang di.

Tabel 7. Rekapitulasi perhitungan derajat kejenuhan pada ruas Jalan Jenderal Sudirman

\begin{tabular}{ccc}
\hline \multirow{2}{*}{ Waktu } & Sudirman - Thamrin & Thamrin - Sudirman \\
\cline { 2 - 3 } & DS & DS \\
\hline Pagi & 0,54 & 0,74 \\
\hline Siang & 0,61 & 0,83 \\
\hline Sore & 0,66 & 0,74 \\
\hline Gabungan & 0,66 & 0,83 \\
\hline
\end{tabular}

Hasil perhitungan tabel 7 pembagian volume terbesar dari data survei dengan kapasitas terbesar model masing masing arah di dapatkan hasil seperti pada tabel diatas, ratio perbandingan dapat digunakan untuk menentukan tingkat kinerja ruas jalan Jenderal Sudirman dan dari hasil tabel hubungan antara tingkat pelayanan, karakteristik arus lalu lintas, dan ratio volume terhadap kapasitas (MKJI,1997) tingkat pelayanan jalan berada pada huruf C \& D, dimana $\mathrm{C}$ adalah keadaan pada saat karakter lalu lintas yang arus nya stabil, tetapi kecepatan dan gerak kendaruan dikendalikan, pengemudi dibatasi dalam memilih kecepatan dan D adalah ketika arus mendekati tidak stabil, kecepatun masih dikendalikan.

\section{Tingkat pelayanan (Level Of Service / LOS)}

Berdasarkan hasil yang telah di dapat kan LOS dapat di nilai dengan melakukan perbandingan volume lalu lintas dengan kapasitas dasar jalan (V/C), setelah itu kita dapat membuatkan grafik hubungan antara volume (V/C) dengan kecepatan model greenshieelds dan memasukkan, mengelompokannya ke dalam klasifikasi di ruas jalan tersebut.

Dibawah ini adalah gambar 6 dan gambar 7 gambaran grafik hasil tingkat pelayanan jalan pada ruas Jalan Jenderal Sudirman, masing masing waktu pagi (segi tiga merah), siang (lingkaran hijau), dan sore (bintang biru), Sudirman arah Thamrin.

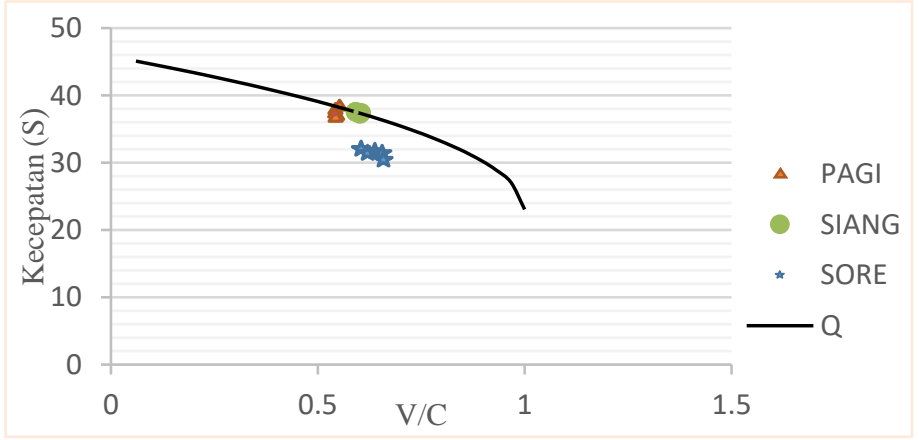

Gambar 6. Grafik tingkat pelayanan Jalan Jenderal Sudirman, sudirman arah Thamrin (pagi, siang, dan sore) 


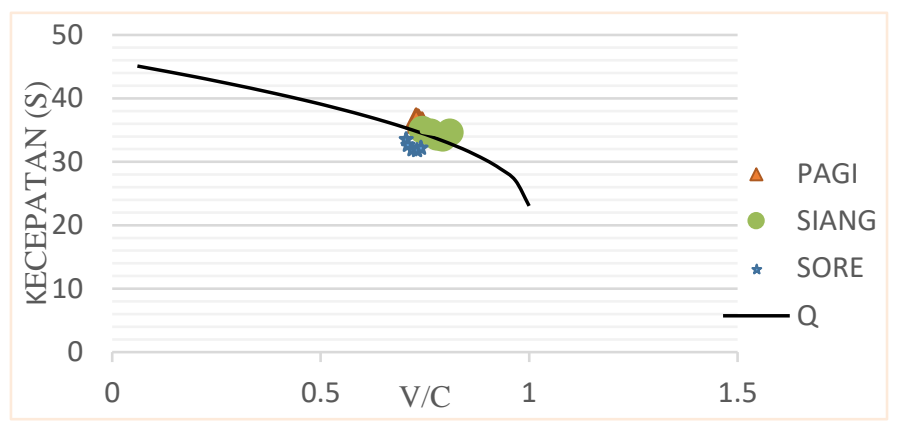

Gambar 7. Grafik tingkat pelayanan Jalan Jenderal Sudirman, thamrin arah Sudirman (pagi, siang dan sore)

Grafik tingkat pelayanan gambar 6 dan gambar 7, di buat dengan melakukan (trial and error) data volume (V) sebanyak 25 buah data Q dari yang paling terkecil sampai yang terbesar yang nilainya mendekati nilai kapasitas terbesar masing - masing ruas yaitu 8.272,535 smp/jam dan 8.067,913 smp/jam, lalu V di bagi dengan nilai $\mathrm{C}$ (kapasitas terbesarnya), dan menghitung nilai $\mathrm{S}$ (kecepatan) dengan meggunakan rumus persamaan hubungan volume dengan kecepatan yaitu sebagai berikut:

1. $\mathrm{V}=\mathrm{D}_{\mathrm{j}} \times \mathrm{S}-\left(\frac{D j}{S F f}\right) \times \mathrm{S}^{2}$

Lalu setelah tergambarkan grafik hubungannya, masukkan data volume dan kecepatan hasil survei pagi, siang, dan sore masing - masing arah. Setelah itu bandingkan data data hasil survei yang sudah berkumpul dengan gambar 1 grafik tingkat pelayanan, hasil memperlihatkan bahwa Tingkat pelayanan di kedua arah untuk ruas jalan Jenderal Sudirman, sudirman arah thamrin (gambar 6), pada pagi, siang dan sore hari titik berbentuk segitiga, bulat, dan bintang berkumpul pada daerah grafik yang masuk ke dalam pelayanan huruf $\mathbf{C}$, yang berarti adalah keadaan arus stabil tetapi kecepatan dan gerakkan kendaraan di kendalikan, pengemudi dibatasi dalam memilih kecepatan. Sedangkan ruas Jalan Jenderal Sudirman, thamrin arah sudirman (gambar 7), pada pagi dan sore hari titik berbentuk segitiga, dan bintang berkumpul pada daerah grafik yang masuk ke dalam pelayanan huruf $\mathbf{C}$, yang berarti adalah keadaan arus stabil tetapi kecepatan dan gerakkan kendaraan di kendalikan, pengemudi dibatasi dalam memilih kecepatan dan pada siang hari titik berbentuk bulat berkumpul pada daerah grafik yang masuk ke dalam pelayanan huruf $\mathbf{D}$, yang berarti adalah arus mendekati tidak stabil, kecepatan masih dikendalikan.

\section{Pembahasan}

Dari hasil data yang telah diperhitungkan dan telah di analisis di atas, berikut ini adalah pembahasannya yaitu :

1. Dari gambar grafik model greenshields di atas dapat dilihat bahwa grafik untuk arah Sudirman - Thamrin (gambar 2) kecepatan tertinggi terjadi pada waktu pagi hari, dan kecepatan terendah terjadi pada waktu sore hari.

2. Dari gambar grafik model greenshields di atas dapat dilihat bahwa grafik untuk arah Thamrin - Sudirman (gambar 4) kecepatan tertinggi terjadi juga pada waktu pagi hari, dan kecepatan terendah terjadi pada waktu sore hari.

3. Kecepatan arus bebas MKJI adalah sebesar $\mathbf{5 5 , 6 8 1 8 ~} \mathbf{~ k m / j a m , ~ k e c e p a t a n ~ a r u s ~ b e b a s ~ m o d e l ~ G r e e n s h i e l d s ~ y a n g ~}$ terendah berada pada waktu sore (Sudirman - Thamrin) dan siang (Thamrin - Sudirman), semakin rendah kecepatannya semakin padat ruas suatu jalan sampai dengan kecepatan sama dengan 0.

4. Kapasitas MKJI adalah sebesar 4.691,53 smp/jam, kapasitas model Greenshields terbesar pada waktu siang hari di kedua arahnya.

5. Pada hasil perhitungan derajat kejenuhan ruas Jalan Jenderal Sudirman untuk kedua arahnya tingkat pelayanan jalan berada pada huruf C \& D. Kinerja lalin yang baik ialah ketika nilai derajat kejenuhannya rendah dan menjadikan kecepatan tempuhnya tinggi dan pengguna jalan dapat merasakan kenyamanan dan bebas saat berada / menggunakan jalan tersebut.

6. Tingkat pelayanan di kedua arah berdasarkan grafik gambar 6 \& 7 adalah sebagai berikut : Ruas Jalan Jenderal Sudirman, Sudirman - Thamrin (gambar 6)

- Pada Pagi Siang dan Sore hari titik berbentuk segitiga, bulat, dan bintang berkumpul pada daerah grafik yang masuk ke dalam pelayanan huruf $\mathbf{C}$, yang berarti adalah keadaan arus stabil tetapi kecepatan dan gerakkan kendaraan di kendalikan, pengemudi dibatasi dalam memilih kecepatan. 
Ruas Jalan Jenderal Sudirman, Sudirman - Thamrin (gambar 7)

- Pada Pagi dan Sore hari titik berbentuk segitiga, dan bintang berkumpul pada daerah grafik yang masuk ke dalam pelayanan huruf $\mathbf{C}$, yang berarti adalah keadaan arus stabil tetapi kecepatan dan gerakkan kendaraan di kendalikan, pengemudi dibatasi dalam memilih kecepatan.

- Pada Siang hari titik berbentuk bulat berkumpul pada daerah grafik yang masuk ke dalam pelayanan huruf $\mathbf{D}$, yang berarti adalah Arus mendekati tidak stabil, kecepatan masih dikendalikan.

\section{KESIMPULAN DAN SARAN}

\section{Kesimpulan}

Dari hasil penelitian data yang telah diperhitungkan dan telah di analisis di atas setelah semuanya selesai di buat, dapat di tarik kesipulan sebagai berikut :

1. Seharusnya kapasitas jalan berdasarkan MKJI harus lebih besar dari volume lalu lintas di jam sibuk, tetapi pada kenyataanya setelah di lakukan analisis kapasitas MKJI lebih kecil nilainya dari volume lalu lintas jam sibuk, sehingga dinperlukan perhitungan kapasitas dengan model agar kapasitas memenuhi syarat lalu lintas dan lebih ideal.

2. Dari gambar grafik model greenshields di atas dapat dilihat bahwa grafik untuk arah Sudirman - Thamrin (gambar 2) kecepatan tertinggi terjadi pada waktu pagi hari yaitu sebesar $\mathbf{3 8 , 1 0 8} \mathbf{~ k m / j a m ~ d e n g a n ~}$ kepadatannya sebesar 117,8458 $\mathbf{~ m m p / j a m , ~ d a n ~ k e c e p a t a n ~ t e r e n d a h ~ t e r j a d i ~ p a d a ~ w a k t u ~ s o r e ~ h a r i ~ y a i t u ~ s e b e s a r ~}$ $30,684 \mathrm{~km} / \mathbf{j a m}$ dengan kepadatannya sebesar 179,3431 smp/jam. Sedangkan dari gambar grafik model greenshields di atas dapat dilihat bahwa grafik untuk arah sebaliknya yaitu Thamrin - Sudirman (gambar 4) kecepatan tertinggi terjadi pada waktu pagi hari yaitu sebesar $\mathbf{3 7 , 0 7 5} \mathbf{~ k m / j a m ~ d e n g a n ~ k e p a d a t a n n y a ~ s e b e s a r ~}$ $\mathbf{1 6 2 , 6 1 2 5} \mathrm{smp} / \mathbf{j a m}$, dan kecepatan terendah terjadi pada waktu sore hari yaitu sebesar 33,265 $\mathbf{~ k m / j a m ~ d e n g a n ~}$ kepadatannya sebesar 179,4474 smp/jam. Kecepatan akan menurun apabila kepadatan bertambah, sampai dengan kecepatan sama dengan 0 yang erarti kepadatan dalam keadaan terjadi kemacetan.

3. Dari hasil perhitungan volume kapasitas dapat di tarik kesimpulan bahwa MKJI 1997 penafsirannya kurang tepat dan terlalu kecil bila dibandingan dengan keadaan lalu lintas pada saat sekarang dan di kondisi berbeda.

4. Berdasarkan data hasil pengamatan dapat disimpulkan bahwa peningkatan volume kendaraan tidak hanya terjadi pada saat pagi ketika orang banyak berangkat kerja dan memulai aktivitas atau pun malam ketika semua orang kembali pulang setelah melakukan aktivitas di luar rumah, tetapi juga terjadi pada siang hari di kedua arah ruas Jalan Jenderal Sudirman juga terpantau padat dengan volume kapasitas terbesar terjadi pada saat siang hari.

5. Pada gambar grafik 6 dan 7 menjelaskan dan menampakkan bahwa pada ruas Jalan Jenderal Sudirman di kedua arah nya masuk ke tingkat pelayanan $\mathbf{C}$ dan $\mathbf{D}$, dimana $\mathbf{C}$ keadaan arus stabil tetapi kecepatan dan gerakkan kendaraan di kendalikan, pengemudi dibatasi dalam memilih kecepatan sedangkan $\mathbf{D}$ adalah keadaan saat arus mendekati tidak stabil, kecepatan masih dikendalikan.

\section{Saran}

Adapun saran yang dapat diberikan setelah penelitian ini selesai dibuat yaitu sebagai berikut :

1. Dari hasil data perhitungan yang telah dilakukan menunjukkan bahwa volume lalu lintas pada ruas Jalan Jenderal Sudirman di kedua arah dan pada saat pagi, siang dan sore sama - sama terpantau padat dan tinggi sehingga dibutuhkan manajaemen lalu lintas yang lebih tepat lagi oleh pemerintah dan diharapkan dapat mengurangi serta mengatasi kemacetan akibat kepadatan lalu lintas di jalan ini.

2. Penelitian yang sama perlu dilakukan pada ruas-ruas jalan yang lainnya yang memilikki nilai hambatan dan kepadatan yang berbeda.

3. Perlu melakukan survei lalu lintas satu hari penuh untuk mendapatkan lebih banyak variasi kondisi lalu lintas danak urasi yang lebih tepat.

\section{DAFTAR PUSTAKA}

Adiel Lorenzo Giovanni. Pengaruh Electronic Road Pricing terhadap Perbaikkan Pelayanan Waktu Tunggu Dan Waktu Tempuh Transjakarta Pada Ruas Jalan Sudirman - Thamrin. 2020. Universitas Tarumanagara

Departemen Pekerjaan Umum. Manual Kapasitas Jalan Indonesia. Direktorat Jenderall Bina Marga. 1997. Jakarta.

Dikdik Sunardi, Ida Farida, Agus Ismail, Studi Analisis Hubungan, Keceptan, Volume, Dan Kepadatan Di Jalan Merdeka Kabupaten Garut Dengan Metode Greenshield. Vol. 11. 2013. Jurnal STT-Garut All Right Reserved. no.1. 
Eko Nugroho. Hubungan Antara Kecepatan, Volume, dan Kepadatan Lalu Lintas Ruas Jalan Siliwangi Semarang. Vol. 12. 2010. Jurnal Teknik Sipil \& Perencanaan. (no.4): Hal 151 -160.

Najid. Evaluation of Side Friction In IHCM For Highway 2 Lanes 2 Ways, ISTSDC. 2019.

Ofyar Z Tamin. Perencanaan, Permodelan, dan Rekayasa Transportasi. ITB. 2008. Bandung. 
